\title{
Relational Contracts in a Persistent Environment
}

\author{
Suehyun Kwon*
}

April 10, 2013

\begin{abstract}
This paper studies relational contracts with partially persistent states, where the distribution of the state depends on the previous state. When the states are observable, with both exogenous and endogenous states, the optimal contract can be stationary, and an effort schedule can be implemented with a stationary contract if and only if it satisfies the IC constraint and the dynamic enforcement constraint. The paper shows how the joint surplus in the second best varies with the state. The paper then applies the results to study implications for markets where the principal and the agent can be matched with new partners. (JEL C73, D86, L14)
\end{abstract}

\section{Introduction}

Most literature assumes that in a repeated interaction, the states are independent and identically distributed over time. But the real-world interactions don't always take place in an i.i.d. environment. A shock to the cost of raw material is likely to persist for some time, and if it becomes costly to perform a task this year, a firm may not expect the cost of performing the task next year to be distributed in the same way as it would after a good year. The production technology this period can also depend on the past realization of the productivity. Anticipating the persistence of the states, the employers may not expect the same effectiveness of the compensation scheme every period, and the optimal compensation scheme may in fact depend on the state.

I study a relational contract model similar to that of Levin (2003) when the states are partially persistent and there is moral hazard. The principal and the agent trade every

\footnotetext{
*Kwon: University College London, suehyun.kwon@ucl.ac.uk, Department of Economics, University College London, Gower Street, London, WC1E 6BT United Kingdom. I'm very grateful to Glenn Ellison. I thank Michael Powell, Juuso Toikka, Muhamet Yildiz and lunch seminar participants at MIT for helpful comments. I also thank Samsung Scholarship for financial support.
} 
period over an infinite horizon, and both parties are risk-neutral with a common discount factor. At the beginning of each period, the payoff-relevant state is realized and becomes observable to both the principal and the agent. Under a relational contract, the principal offers a compensation scheme each period, and the agent decides whether or not to accept it and how much effort to exert if he accepts the offer. The principal doesn't observe the agent's effort, which leads to moral hazard, but he observes the outcome, which is a noisy signal of the agent's effort, and therefore can promise contingent payments on outcome.

The main results of the paper are in two parts. I characterize the optimal relational contracts, both for exogenous states and endogenous states, and show that the optimal contracts can be stationary. The second part applies the results to study the markets for random matching.

There is a large literature on relational contracts, including Levin (2003) and Baker, Gibbons, and Murphy (2002). ${ }^{1}$ More recent papers consider environments with asymmetric information, and most of the literature assumes that the environment is either stationary or i.i.d. over time. My paper is most closely related to Levin (2003), where he shows that for i.i.d. states, the principal can focus on maximizing the joint surplus and the optimal contracts can be stationary. The necessary and sufficient condition to implement an effort schedule with stationary contracts is that it satisfies the IC constraint and one other constraint. The optimal contract either implements the first best or is a step function. Other related literature is discussed at the end of this section.

Section 3 considers the results that hold for any type of persistence where the states evolve exogenously and are observable before the agent exerts effort. As was the case with i.i.d. states, the distribution of the joint surplus between the principal and the agent can be separated from the problem of efficient-contracting, and in characterizing the Paretooptimal contracts, it is sufficient to focus on the joint surplus from the relationship. The principal can always redistribute the surplus through the fixed wage in the initial period. When the states follow a first-order Markov chain, the realization of the state this period is a sufficient static for the distribution of the future states, and the principal can provide all incentives by the bonus payments at the end of this period. It is optimal to provide the same expected per period payoff to the agent in every state, and for each state, the principal can offer a contract that maximizes the joint surplus. In particular, the principal can offer a stationary contract every period. I define stationary contracts as contracts under which the compensation scheme is identical in all periods; the wage and bonus payments are allowed to depend on the realization of the state and the outcome in the given period, but they don't

\footnotetext{
${ }^{1}$ Earlier literature on relational contracts focused on symmetric information case. See for example, Shapiro and Stiglitz (1984), Bull (1987), MacLeod and Malcomson (1989), Kreps (1990).
} 
depend on the history. Under a relational contract, there is a temptation to renege, and the self-enforcement leads to the dynamic enforcement constraint as in the i.i.d. case. The necessary and sufficient condition for an effort schedule to be implementable by a stationary contract is that it satisfies the IC constraint and the dynamic enforcement constraint. I also show that the optimal contract either implements the first best level of effort, or it takes the form of a step function.

In Section 4, I consider an alternative model in which the state is endogenous. From an applied perspective, there are often environments where the agent's effort affects the distribution of the state. Specifically, I consider the environment in which the productivity is the state variable. The distribution of productivity for the next period depends on the current productivity and the agent's effort, which implies that the agent's effort affects the distribution of states in all future periods. When the productivity is observable and the persistence is of first-order, however, most results in Section 3 generalize to this environment. The distribution of the joint surplus between the principal and the agent can be separated from the problem of efficient contracting, and the optimal contract can still be stationary. The productivity is a sufficient static for the distribution of future states, and the principal can still provide all incentives by the compensation scheme at the end of the period. The principal can offer a stationary contract that leaves the agent indifferent between accepting and rejecting the offer. I also show a version of dynamic enforcement constraint which is, together with the IC constraint, the necessary and sufficient condition to implement an effort schedule with such stationary contracts.

I also consider two mechanisms through which the persistence of the states affect relational contracts. When the states are persistent, the joint surplus in the first best can vary with the state, and incentive provision for given bonus cap can also vary with the state. I consider two mechanisms separately, holding the other constant. I find that in both cases, if the joint surplus in the first best increases with the state, or if the implementable level of effort for given bonus cap increases with the state, the difference in the joint surplus between the first best and the second best decreases with the state. The principal prefers relational contracts to full-commitment contracts if and only if the initial state is sufficiently high.

The next section discusses the implications for the markets for random matching where the principal and the agent can be randomly, anonymously, and costlessly matched with new partners. The nature of the state leads to starkly different implications for the market. The degree of cooperation varies with the nature of the state, and it also highlights the difference between the i.i.d. states and the persistent states. The key step is to consider the bonus cap from the dynamic enforcement constraint. When the states are i.i.d., or if the states are persistent but common to all principal-agent pairs, cooperation is impossible; the parties 
cannot credibly promise any bonus payment, and the principal cannot induce any level of effort from the agent. On the other hand, if the state is persistent and agent-specific, the market turns into the market for lemons, and there is no market. The principal and the agent stay in the same relationship forever. If the state is persistent and relationship-specific, there will be a market, and the principal and the agent leave the current relationship if and only if the expected joint surplus falls below some threshold.

There are some papers on relational contracts with persistent states. Thomas and Worrall (2010) consider a two-sided incentive problem where the states and the efforts are observable and the players have limited liability. McAdams (2011) considers joint-partnership games in which the states are persistent and both the states and efforts are observable. The players decide whether to stay in the relationship and how much effort to exert. The main difference from my model is that there is no asymmetric information in their models, and there is limited liability in Thomas and Worrall.

In Kwon (2012), I consider moral hazard with persistent states and full-commitment. States are unobservable in Kwon (2012). Garrett and Pavan (2011, 2012) have moral hazard and persistent private information. There are also papers on dynamic adverse selection with persistent private information. Athey and Bagwell (2008) study collusion with private cost shocks, and Battaglini (2005) considers consumers with Markovian types. Escobar and Toikka (2012) show folk theorem results for Markovian types and communication.

The market setting in my paper is related to literature on repeated games with rematching. Ghosh and Ray (1996), Kranton (1996) and Watson (1999) among others consider repeated interactions when the players can exit the relationship in any period. The stage game in these papers are similar to the prisoner's dilemma, and most of them don't have monetary transfers. The equilibrium strategy is often to start small, which contrasts with the stationary behavior in my model.

Lastly, this paper is also related to literature on partnership games with persistent states. Rotemberg and Saloner (1996) and Haltiwanger and Harrington (1991) study collusion in nonstationary markets. In Rotemberg and Saloner, the potential gain from deviating is higher in a higher state, and the future surplus is not affected by the state. In my first model of Section 5, the gain from deviating is constant across the states, and it is the future surplus that varies with the state; my model is closer to Haltiwanger and Harrington.

The rest of the paper is organized as the following. Section 2 describes the model, and the general results are presented in Section 3. I consider an alternative model in Section 4 in which the state variable is endogenous. Section 5 discusses the types of persistent states and their implications on the joint surplus in the second best. Section 6 applies the results for the markets for random matching. Section 7 concludes. 


\section{Model}

The principal and the agent have the opportunity to trade over an infinite horizon, $t=$ $0,1,2, \cdots$. Both the principal and the agent are risk-neutral, and the common discount factor is $\delta<1$.

The principal has limited commitment power and can only employ relational contracts. At the beginning of period $t$, the principal offers a compensation scheme to the agent, which consists of a fixed salary $w_{t}$ and a contingent payment $b_{t}$. Both the fixed salary and the contingent payment can be functions of the history, which I will define momentarily. The agent decides whether to accept the offer, and a payoff-relevant parameter $\theta_{t}$ is realized. Both the principal and the agent observe the state. Note that the principal offers the compensation scheme before the realization of the state; he offers a function of the state as fixed salary, and the bonus payment is a function of the performance outcome.

Timing in Each Period

\begin{tabular}{cccccc}
\hline & $\mid$ & & & & \\
Principal & Agent & $\theta_{t}$ becomes & Agent & Outcome $y_{t}$ & Bonus \\
makes & accepts & observable. chooses $e_{t}$. & is realized. & payment \\
an offer. & /rejects. & & & & is made.
\end{tabular}

The state $\theta_{t}$ is drawn from the support $\Theta=[\underline{\theta}, \bar{\theta}]$. The distribution of the state $\theta_{t}$ depends only on the previous state $\theta_{t-1}$. Denote the distribution of $\theta_{t}$ by $P\left(\theta_{t} \mid \theta_{t-1}\right)$. The distribution of the state doesn't depend on the time index, and we have $P\left(\theta_{t} \mid \theta_{t-1}\right)=P\left(\theta_{1} \mid \theta_{0}\right)$ for all $t \geq 1$. In the initial period, the state $\theta_{0}$ is distributed by $P_{0}\left(\theta_{0}\right)$. The distributions $P\left(\theta_{t} \mid \theta_{t-1}\right)$ and $P_{0}\left(\theta_{0}\right)$ are known to both the principal and the agent.

Assumption 1. The distribution of state $\theta_{t+1}$ when the previous state was $\theta_{t}$ is given by $P\left(\theta_{t+1} \mid \theta_{t}\right)$ and is identical for all $t \geq 0$.

After the principal offers a compensation scheme, the agent decides whether or not to accept, $d_{t} \in\{0,1\}$. If the agent accepts the compensation scheme, the agent chooses how much effort to exert, $e_{t} \in \mathcal{E}=[0, \bar{e}]$. The cost of effort, $c\left(e_{t}, \theta_{t}\right)$, increases with $e$ with $c(e=0, \theta)=0$ for all $\theta$ and $c_{e e}>0$. The agent's effort generates outcome $y_{t}$ with the distribution $F(y \mid e, \theta)$ and the support $\mathcal{Y}=[y, \bar{y}]{ }^{2}$ The expected per period joint surplus can be written as a function of $\theta$ and $e, S(e, \theta)=\mathbb{E}[y \mid e, \theta]-c(e, \theta)$. Throughout the paper, when capitalized, $S(e, \theta)$ denotes per-period joint surplus in state $\theta$ if the agent chooses effort $e$.

\footnotetext{
${ }^{2}$ Most results of the paper hold for any distribution of the outcome.
} 
I allow the distribution of the outcome and the cost function to be dependent on the state. If neither of them depends on the state, we are back to i.i.d. environment, and in general, we can have one or the other to be state-dependent.

Each period, there are three pieces of payoff-relevant information: the cost-relevant parameter $\theta_{t}$, the agent's effort $e_{t}$, and the outcome $y_{t}$. The agent observes all three parameters, but the principal observes only $\theta_{t}$ and $y_{t}$. The performance outcome is $\phi_{t}=\left\{\theta_{t}, y_{t}\right\}$, and the set of all performance outcome is denoted by $\Phi$.

At the end of each period, the principal is obliged to pay the fixed salary $w_{t}$, but the contingent payment is only promised. Denote the total payment to the agent by $W_{t}$, and $W_{t}=w_{t}+b_{t}$ if the contingent payment is made, and it is $W_{t}=w_{t}$ if not.

If the agent rejects the principal's offer, the parties receive their outside option for the period. The agent's outside option is $\bar{u}$, and the principal's outside option is $\bar{\pi}$. The joint surplus from the outside option is denoted by $\bar{s}=\bar{u}+\bar{\pi}$.

Assumption 2 (Efficiency). The maximum joint surplus is strictly bigger than the outside option for any state, but the outside option is weakly better than no effort. For all $\theta \in \Theta$, $\max _{e} S(e, \theta)>\bar{s} \geq S(0, \theta)$.

I assume that for any state $\theta$, the maximum joint surplus is strictly bigger than the outside option, but the outside option is weakly better than no effort. I also assume that the outside options $\bar{u}, \bar{\pi}$ are independent of the state and constant over time. In Section 6 , I consider markets for random matching, and there will be endogenous outside options.

Given the distribution of the states, $P\left(\theta_{t+1} \mid \theta_{t}\right)$, we can define the distribution of $\theta_{t+\tau}$ given $\theta_{t}, P\left(\theta_{t+\tau} \mid \theta_{t}\right)$. Let $p\left(\theta_{t+1} \mid \theta_{t}\right)$ be the pdf of $\theta_{t+1}$, then we have

$$
p\left(\theta_{t+\tau} \mid \theta_{t}\right)=\int \cdots \int p\left(\theta_{t+\tau} \mid \theta_{t+\tau-1}\right) \cdots p\left(\theta_{t+1} \mid \theta_{t}\right) d \theta_{t+\tau-1} d \theta_{t+1},
$$

and $P\left(\theta_{t+\tau} \mid \theta_{t}\right)$ can be constructed from $p\left(\theta_{t+\tau} \mid \theta_{t}\right)$. The discounted payoffs to the parties from date $t$ given $\theta_{t-1}$ are

$$
\begin{aligned}
& u_{t}\left(\theta_{t-1}\right)=(1-\delta) \mathbb{E}\left[\sum_{\tau=t}^{\infty} \delta^{\tau-t}\left\{d_{\tau}\left(W_{\tau}-c\left(e_{\tau}, \theta_{\tau}\right)\right)+\left(1-d_{\tau}\right) \bar{u}\right\} \mid \theta_{t-1}\right], \\
& \pi_{t}\left(\theta_{t-1}\right)=(1-\delta) \mathbb{E}\left[\sum_{\tau=t}^{\infty} \delta^{\tau-t}\left\{d_{\tau}\left(y_{\tau}-W_{\tau}\right)+\left(1-d_{\tau}\right) \bar{\pi}\right\} \mid \theta_{t-1}\right],
\end{aligned}
$$

where the expectations are taken over $P\left(\theta_{\tau} \mid \theta_{t-1}\right), \tau \geq t$, and $F(\cdot \mid e, \theta)$. In period 0 , the expectation is also taken over $P_{0}\left(\theta_{0}\right)$. At each period, the parties maximize their expected 
payoffs. I define the expected joint surplus from period $t$ as

$$
s_{t}\left(\theta_{t-1}\right)=u_{t}\left(\theta_{t-1}\right)+\pi_{t}\left(\theta_{t-1}\right) .
$$

Note that $s_{t}\left(\theta_{t-1}\right)$ is the per period average expected joint surplus, as it is discounted by $1-\delta$. When capitalized, $S(e, \theta)$ is the expected joint surplus from the given period for $e, \theta$.

Let $h^{t}=\left(w_{0}, d_{0}, \phi_{0}, W_{0}, \cdots, w_{t-1}, d_{t-1}, \phi_{t-1}, W_{t-1}\right)$ be the history up to period $t$ and $\mathcal{H}^{t}$ be the set of possible period $t$ histories. Given any period $t$ and history $h^{t}$, a relational contract specifies the compensation the principal offers, whether or not the agent accepts it, and if the agent accepts the offer, the effort level. The compensation $w_{t}, b_{t}$ are allowed to be functions of the history, and they are functions of the following form:

$$
\begin{aligned}
w_{t}: \mathcal{H}^{t} \times \Theta & \rightarrow \mathbb{R}, \\
b_{t}: \mathcal{H}^{t} \times \Phi & \rightarrow \mathbb{R} .
\end{aligned}
$$

A relational contract is self-enforcing if it forms a perfect public equilibrium of the repeated game.

\section{Observable and Exogenous States}

This section discusses the results that hold for any type of persistent states. The main results of this section generalize the characterization in Levin (2003) to persistent states. When the states are observable and exogenously given, the optimal contract can be stationary, and it is optimal to provide the same expected per period payoff in every state. The self-enforcement leads to the dynamic enforcement constraint as with i.i.d. states. An optimal contract either implements the first best level of effort or takes the form of a step function.

A relational contract forms a perfect public equilibrium of the repeated game, and there is multiplicity of equilibria. Instead of characterizing all relational contracts, I focus on efficient contracting and focus on the Pareto Frontier of the payoffs. The first result is to note that the problem of efficient contracting can be separated from the problem of distribution even if the states are persistent. The intuition is same as in Levin (2003). The principal can always adjust the fixed salary to redistribute the surplus.

Proposition 1. Suppose there exists a relational contract with expected joint surplus $s>\bar{s}$. Any expected payoff pair $(u, \pi)$ with $u \geq \bar{u}, \pi \geq \bar{\pi}, u+\pi=s$ can be implemented with a relational contract.

Proof. Consider the relational contract that provides $s$. The principal offers in the initial 
period $w\left(\theta_{0}\right), b\left(\phi_{0}\right)$, and if the agent accepts, he exerts effort $e\left(\theta_{0}\right)$. The continuation payoffs under the contract are denoted by $u\left(\phi_{0}\right)$ and $\pi\left(\phi_{0}\right)$, and the expected payoffs from the contract are $u_{0}$ and $\pi_{0}$. Without loss of generality, we can assume that off the equilibrium path, the parties revert to the static equilibrium of $(\bar{u}, \bar{\pi})$. The first period payment $W$ is a function of $\phi_{0}$.

The contract is self-enforcing if and only if the following conditions hold:

$$
\begin{aligned}
& \text { (i) } u_{0} \geq \bar{u}, \pi_{0} \geq \bar{\pi} \\
& \text { (ii) } e\left(\theta_{0}\right) \in \arg \max _{e} \mathbb{E}_{y}\left[(1-\delta) W\left(\phi_{0}\right)+\delta u\left(\phi_{0}\right) \mid e, \theta_{0}\right]-c\left(e, \theta_{0}\right), \\
& \text { (iii) } b\left(\phi_{0}\right)+\frac{\delta}{1-\delta} u\left(\phi_{0}\right) \geq \frac{\delta}{1-\delta} \bar{u}, \\
& \quad-b\left(\phi_{0}\right)+\frac{\delta}{1-\delta} \pi\left(\phi_{0}\right) \geq \frac{\delta}{1-\delta} \bar{\pi},
\end{aligned}
$$

and (iv) each continuation contract is self-enforcing.

Given any $(u, \pi)$ such that $u \geq \bar{u}, \pi \geq \bar{\pi}, u+\pi=s$, the principal can offer the same $b\left(\phi_{0}\right)$ and continuation contracts and adjust $w\left(\theta_{0}\right)$ to

$$
\hat{w}\left(\theta_{0}\right) \equiv w\left(\theta_{0}\right)+\frac{\pi-\pi_{0}}{1-\delta} .
$$

The conditions are satisfied with the new contract, and it provides $(u, \pi)$ as the expected payoffs.

As long as the expected payoff is greater than the outside option, the parties are willing to initiate the contract. The principal can adjust the distribution of the joint surplus by the fixed salary of the initial period, and the resulting contract is still self-enforcing because the incentives are not affected. Given Proposition 1, we can restrict attention to optimal relational contracts that maximize the joint surplus from the contract.

The next result is that despite the persistence of the states, the maximum joint surplus can be acheived with stationary contracts. I define the stationarity of a contract as the following:

Definition 1. A contract is stationary if $W_{t}=w\left(\theta_{t}\right)+b\left(\phi_{t}\right), e_{t}=e\left(\theta_{t}\right)$ at every $t$ on the equilibrium path for some $w: \Theta \rightarrow \mathbb{R}, b: \Phi \rightarrow \mathbb{R}$ and $e: \Theta \rightarrow \mathcal{E}$.

Note that the contract is stationary on the equilibrium path. Without loss of generality, we can assume that off the equilibrium path, the parties revert to the static equilibrium of taking the outside option every period, $(\bar{u}, \bar{\pi})$. With a stationary contract, the principal offers the identical compensation scheme every period. The compensation scheme is independent 
of the history, and it only depends on the performance outcome of the given period. The fixed salary may depend on the state, but given the same state, the fixed salary is constant across the time.

Proposition 2. The maximum joint surplus can be attained with a stationary contract. Furthermore, it can be achieved with a contract that provides the same expected payoff to the agent in every state.

Proof. Suppose a contract that maximizes the joint surplus provides $w_{t}, b_{t}$ and the agent chooses $e_{t}$. The first step is to construct an alternative contract $\hat{w}_{t}, \hat{b}_{t}$ under which the agent chooses the same level of effort $e_{t}$ and his expected payoff is constant in every state.

When the states are observable and exogenously given, the distribution of the states from period $t+1$ only depends on $\theta_{t}$, and the outcome $y_{t}$ doesn't carry any information about the future states. The principal can adjust the contingent payment $b_{t}$ and keep the expected payoff in each state constant. Specifically, consider the following contract. Let $u_{t}\left(h^{t}, \phi_{t}\right)$ be the continuation value of the agent under the given contract, and define $\hat{w}_{t}, \hat{b}_{t}$ as the following:

$$
\begin{aligned}
& \hat{b}_{t}\left(h^{t}, \phi_{t}\right) \equiv b_{t}\left(h^{t}, \phi_{t}\right)+\frac{\delta}{1-\delta}\left(u_{t}\left(h^{t}, \phi_{t}\right)-\bar{u}\right), \\
& \hat{w}_{t}\left(h^{t}, \theta_{t}\right) \equiv \bar{u}-\mathbb{E}_{y_{t}}\left[\hat{b}_{t}\left(h^{t}, \phi_{t}\right) \mid e_{t}\left(h^{t}, \theta_{t}\right)\right] .
\end{aligned}
$$

From

$$
\hat{b}_{t}\left(h^{t}, \phi_{t}\right)+\frac{\delta}{1-\delta} \bar{u}=b_{t}\left(h^{t}, \phi_{t}\right)+\frac{\delta}{1-\delta} u_{t}\left(h^{t}, \phi_{t}\right),
$$

the agent chooses the same level of effort $e_{t}$ under the new contract. The agent's expected payoff is $\bar{u}$ for all $t, h^{t}, \theta_{t}$.

The next step is to show that we can choose $\tilde{w}: \Theta \rightarrow \mathbb{R}, \tilde{b}: \Phi \rightarrow \mathbb{R}$ such that the principal offers $\tilde{w}, \tilde{b}$ in every period. Consider $\hat{w}_{t}$ and $\hat{b}_{t}$. The agent's expected payoff is constant over all $t, h^{t}$, and $\theta_{t}$, which implies that the agent's IC constraint is determined by the within period compensation scheme. Specifically, the agent chooses $e$ such that

$$
e_{t}\left(h^{t}, \theta_{t}\right) \in \arg \max _{e} \mathbb{E}_{y}\left[\hat{b}_{t}\left(h^{t}, \phi_{t}\right) \mid e, \theta_{t}\right]-c\left(e, \theta_{t}\right)
$$

When the agent's IC constraints are myopic, the principal can replace a compensation scheme for any given period with another compensation scheme without affecting the incentives. The principal can also treat each $\theta_{t}$ separately, because the state is observable before the agent chooses the effort. Specifically, let $\tilde{b}$ be the compensation scheme that maximizes 
the expected per period joint surplus for state $\theta_{t}$ :

$$
\tilde{b}\left(\theta_{t}, \cdot\right) \equiv \arg \max _{\hat{b}_{t}\left(h^{t},\left\{\theta_{t}, \cdot\right\}\right)} \mathbb{E}_{y}\left[y \mid e_{t}\left(h^{t}, \theta_{t}\right), \theta_{t}\right]-c\left(e_{t}\left(h^{t}, \theta_{t}\right), \theta_{t}\right)
$$

If there's multiplicity of the compensation schemes, we can pick one without loss of generality.

Given $\tilde{b}: \Phi \rightarrow \mathbb{R}$, the agent chooses $e: \Theta \rightarrow \mathcal{E}$ such that

$$
e\left(\theta_{t}\right) \in \arg \max _{e} \mathbb{E}_{y}\left[\tilde{b}(\phi) \mid e, \theta_{t}\right]-c\left(e, \theta_{t}\right)
$$

Define $\tilde{w}$ as

$$
\tilde{w}\left(\theta_{t}\right) \equiv \bar{u}-\mathbb{E}_{y}\left[\tilde{b}(\phi) \mid e\left(\theta_{t}\right), \theta_{t}\right]
$$

and we have a stationary contract that maximizes the expected joint surplus. By construction, it is self-enforcing, and it provides the same expected payoff to the agent in all $t, h^{t}, \theta_{t}$. Let $s^{*}$ be the minimum expected per period joint surplus over the states under $\tilde{b}, \tilde{w}$ :

$$
s^{*} \equiv \min _{\theta}\left\{\mathbb{E}_{y}[y \mid e(\theta), \theta]-c(e(\theta), \theta)\right\}
$$

The principal can adjust the fixed salary and can provide any $u$ such that $\bar{u} \leq u \leq s^{*}-\bar{\pi}$ to the agent as the constant expected payoff.

From Propositions 1 and 2, we can focus on stationary contracts that maximize the joint surplus. I will next provide the necessary and sufficient condition for an effort schedule to be implementable by a stationary contract. When the states are observable and exogenously given, there is no information asymmetry about the distribution of future states. For the agent's IC constraints, only the sum of the present compensation and the continuation value matters, and in particular, the principal and the agent use the same probability distribution to evaluate the continuation values. Therefore, the principal can provide the incentives by the present compensation and provide the same expected payoff in all periods and all states. By doing so, the principal isolates the incentive provision to each period and the given state, and the principal can offer an identical compensation scheme in all periods for the given state. The maximum joint surplus can be attained with a stationary contract, and we can restrict attention to stationary contracts that maximize the joint surplus.

With relational contracts, neither the principal or the agent commits to the contingent payment, and there exists a temptation to renege on the promised payment. The contract is self-enforcing if the principal and the agent have no incentives to renege. Since we are interested in the maximum joint surplus, there is no loss of generality in assuming that a deviation leads to the static equilibrium behavior. If the principal offers an unexpected com- 
pensation scheme, the agent accepts the offer but exerts zero effort. Following a deviation, the parties receive their outside options $\bar{\pi}$ and $\bar{u}$.

Recall that when the states are persistent, the discounted payoffs at period $t$ should be conditional on state $\theta_{t-1}$ :

$$
\begin{aligned}
& u_{t}\left(\theta_{t-1}\right)=(1-\delta) \mathbb{E}\left[\sum_{\tau=t} \delta^{\tau-t}\left\{d_{\tau}\left(W_{\tau}-c\left(e_{\tau}, \theta_{\tau}\right)\right)+\left(1-d_{\tau}\right) \bar{u}\right\} \mid \theta_{t-1}\right], \\
& \pi_{t}\left(\theta_{t-1}\right)=(1-\delta) \mathbb{E}\left[\sum_{\tau=t} \delta^{\tau-t}\left\{d_{\tau}\left(y_{\tau}-W_{\tau}\right)+\left(1-d_{\tau}\right) \bar{\pi}\right\} \mid \theta_{t-1}\right],
\end{aligned}
$$

and the expected joint surplus from $t+1$ is $s_{t+1}\left(\theta_{t}\right)=u_{t+1}\left(\theta_{t}\right)+\pi_{t+1}\left(\theta_{t}\right)$.

The principal makes the promised payment if and only if

$$
\frac{\delta}{1-\delta}\left(\pi_{t+1}\left(\theta_{t}\right)-\bar{\pi}\right) \geq \sup _{y} b\left(\theta_{t}, y\right), \forall \theta_{t},
$$

and for the agent to make the promised payment, we need

$$
\frac{\delta}{1-\delta}\left(u_{t+1}\left(\theta_{t}\right)-\bar{u}\right) \geq-\inf _{y} b\left(\theta_{t}, y\right), \forall \theta_{t} .
$$

From Proposition 1, the principal can redistribute the surplus by adjusting the fixed wage, and the above inequalities can be combined in the dynamic enforcement constraint:

$$
(D E) \quad \frac{\delta}{1-\delta}\left(s_{t+1}\left(\theta_{t}\right)-\bar{s}\right) \geq \sup _{y} W\left(\theta_{t}, y\right)-\inf _{y} W\left(\theta_{t}, y\right) .
$$

The enforceable effort schedules are characterized by the agent's IC constraint and the dynamic enforcement constraint.

Proposition 3. An effort schedule $e(\theta)$ with expected joint surplus $s(\theta)$ can be implemented with a stationary contract if and only if there exists a payment schedule $W: \Phi \rightarrow \mathbb{R}$ such that for all $\theta \in \Theta$,

$$
\begin{aligned}
& (I C) \quad e(\theta) \in \arg \max _{e} \mathbb{E}_{y}[W(\phi) \mid e, \theta]-c(e, \theta), \\
& (D E) \quad \frac{\delta}{1-\delta}(s(\theta)-\bar{s}) \geq \sup _{y} W(\theta, y)-\inf _{y} W(\theta, y) .
\end{aligned}
$$

Proof. $(\Rightarrow)$ Suppose $e(\theta)$ is implementable. Let $u(\theta)$ and $\pi(\theta)$ be the continuation value for the agent and the principal when the previous state was $\theta$. The IC constraint has to be 
satisfied, and we also know that

$$
\begin{aligned}
& \frac{\delta}{1-\delta}(\pi(\theta)-\bar{\pi}) \geq \sup _{y} b(\theta, y), \forall \theta, \\
& \frac{\delta}{1-\delta}(u(\theta)-\bar{u}) \geq-\inf _{y} b(\theta, y), \forall \theta
\end{aligned}
$$

have to hold. Adding the two inequalities, we have the dynamic enforcement constraint.

$(\Leftarrow)$ Suppose $W(\phi)$ and $e(\theta)$ satisfy the IC constraint and the dynamic enforcement constraint. Define

$$
\begin{aligned}
b(\phi) & =W(\phi)-\inf _{\phi} W(\phi), \\
w(\theta) & =\bar{u}-\mathbb{E}_{y}[W(\phi) \mid e(\theta), \theta],
\end{aligned}
$$

and consider the stationary contract with $w(\theta), b(\phi)$ and $e(\theta)$. The parties revert to the static equilibrium if a deviation occurs. The agent receives $\bar{u}$ as expected payoff in each state, and the principal receives $\pi(\theta)=s(\theta)-\bar{u}$ if the previous state was $\theta$. By the dynamic enforcement constraint, $s(\theta) \geq \bar{s}$ and $\pi(\theta) \geq \bar{\pi}$ for all $\theta$. From the IC constraint, the agent chooses $e(\theta)$ in each state $\theta$, and it can be verified that Inequality (1) and (2) are satisfied.

Note that the continuation payoffs from period $t+1$ matter in the dynamic enforcement constraint, but they don't enter the agent's IC constraint. Since the states are persistent, the continuation payoffs $u_{t+1}\left(\theta_{t}\right)$ and $\pi_{t+1}\left(\theta_{t}\right)$ depend on the state $\theta_{t}$. But the principal also observes $\theta_{t}$, and by Proposition 2, the principal can offer a stationary continuation contract and the constant continuation value, independent of the outcome $y_{t}$. Therefore, even though the agent's expected payoff from period $t$ is $W\left(\phi_{t}\right)+\delta u_{t+1}\left(\theta_{t}\right), u_{t+1}\left(\theta_{t}\right)=\bar{u}$, and it doesn't matter for the agent's IC constraint.

We also know from the dynamic enforcement constraint that the joint surplus, both in per period and in the expected discounted joint surplus, decrease with the outside option $\bar{s}$.

Proposition 4. The per period joint surplus and the expected joint surplus weakly decrease with the outside option $\bar{s}$.

Proof. From the dynamic enforcement constraint, the bonus cap decreases with the outside option $\bar{s}$. The maximum per period joint surplus weakly decreases with $\bar{s}$, which further suppresses the bonus cap through the expected joint surplus. Therefore, both the per period joint surplus and the expected joint surplus decrease with $\bar{s}$. 
Lastly, from Proposition 3, we obtain the following characterization of optimal contracts. When the distribution of the outcome satisfies the Mirrlees-Rogerson constraints, together with risk-neutrality of both parties, the principal wants to use the strongest incentives possible. If an optimal contract cannot induce the first best effort $e^{F B}\left(\theta_{t}\right)$ in state $\theta_{t}$, the DE constraint binds, and the compensation scheme is a step function.

Assumption 3. The distribution of the outcome $F(y \mid e, \theta)$ satisfies the Mirrlees-Rogerson constraints: $F(y \mid e, \theta)$ has the monotone likelihood ratio property, ( $f_{e} / f$ increases with $\left.y\right)$ and $F(y \mid e, \theta)$ is convex in e for any $\theta$.

Proposition 5. Suppose Assumption 3 holds. An optimal contract either (i) implements $e^{F B}\left(\theta_{t}\right)$ or (ii) takes the form of a step function at each $\theta_{t}$. When $e\left(\theta_{t}\right)<e^{F B}\left(\theta_{t}\right)$, there exists $y\left(\theta_{t}\right)$ such that $W\left(\theta_{t}, y\right)=\bar{W}\left(\theta_{t}\right)$ for $y \geq y\left(\theta_{t}\right)$ and $W\left(\theta_{t}, y\right)=\underline{W}\left(\theta_{t}\right)$ for $y<y\left(\theta_{t}\right)$. $\bar{W}\left(\theta_{t}\right)=\underline{W}\left(\theta_{t}\right)+\frac{\delta}{1-\delta}\left(s_{t+1}\left(\theta_{t}\right)-\bar{s}\right)$, and the likelihood ratio $f_{e} / f\left(y \mid e\left(\theta_{t}\right)\right)$ changes the sign at $y\left(\theta_{t}\right)$.

Proof. We know from Proposition 1 that we can focus on maximizing the joint surplus, and Proposition 2 implies that we can focus on stationary contracts. By the Mirrlees-Rogerson constraints, we can replace the agent's IC constraint with the first-order condition. The optimal stationary contract solves

$$
\max _{e(\cdot), W(\cdot, \cdot)} \mathbb{E}_{\theta, y}[y-c \mid e(\theta), \theta]
$$

subject to

$$
\begin{aligned}
& \frac{d}{d e}\left\{\mathbb{E}_{y}[W(\theta, y)-c(e, \theta) \mid e=e(\theta), \theta]\right\}=0, \forall \theta \\
& \frac{\delta}{1-\delta}(s(\theta)-\bar{s}) \geq \sup _{\theta, y} W(\theta, y)-\inf _{\theta, y} W(\theta, y) \\
& s(\theta)=(1-\delta) \mathbb{E}\left[\sum_{t=0} \delta^{t}\left\{d_{t}\left(y_{t}-c\left(e_{t}, \theta_{t}\right)\right)+\left(1-d_{t}\right) \bar{s}\right\} \mid \theta\right]
\end{aligned}
$$

From the Mirrlees-Rogerson constraints, the principal wants to maximize $e$ when $e\left(\theta_{t}\right)<$ $e^{F B}\left(\theta_{t}\right)$. We get

$$
W\left(\theta_{t}, y\right)=\left\{\begin{array}{ll}
\bar{W}\left(\theta_{t}\right) & \text { if } y \geq y\left(\theta_{t}\right) \\
\underline{W}\left(\theta_{t}\right) & \text { if } y<y\left(\theta_{t}\right) .
\end{array},\right.
$$

and $f_{e}$ changes the sign at $y\left(\theta_{t}\right)$, and $\bar{W}\left(\theta_{t}\right)=\underline{W}\left(\theta_{t}\right)+\frac{\delta}{1-\delta}\left(s_{t+1}\left(\theta_{t}\right)-\bar{s}\right)$.

The results in this section hold for any type of persistence. When the states are observable and exogenously given, there is no asymmetric information between the principal and the 
agent regarding the distribution of future states. Together with risk-neutrality, the principal can provide all incentives by the bonus payments at the end of each period and offer the same continuation value in every state. The results in Levin (2003) extend to persistent states, and we have shown the following results. The problem of efficient contracting can be separated from the problem of distribution, and the joint-surplus can be maximized with stationary contracts. The necessary and sufficient condition to implement an effort schedule with stationary contracts is that it satisfies the IC constraint and the dynamic enforcement constraint. An optimal contract either implements the first best level of effort, or it is a step function in each state.

\section{Endogenous States}

In practice, it is often natural to assume that the state variable is endogenous. Human capital is likely to be developed by the agent's effort over time, and the productivity is also often endogenous. If the outcome this period determines the productivity for the next period, the outcome itself is the state variable and is endogenous. Results in this section show that we can apply the similar analysis to relational contracts with endogenous states, as long as the state is observable to both the principal and the agent.

This section considers an alternative model with endogenous states. The agent's effort and the productivity this period determine the distribution of the productivity next period, and the outcome is a function of the productivity. Since the agent's effort affects the distribution of the productivity, it is an endogenous state variable. However, when the productivity is observable to both the principal and the agent, most of the results in the previous section generalize to this model. Specifically, I show that the problem of efficient contracting can be separated from the distribution of joint surplus, and the maximum joint surplus can be attained with stationary contracts. An effort schedule is implementable with stationary contracts if and only if the IC constraint and the dynamic enforcement constraint are satisfied.

The productivity $\theta_{t}$ is drawn from $\Theta=[\underline{\theta}, \bar{\theta}]$. The distribution of $\theta_{t}$ depends on $\theta_{t-1}$ and $e_{t-1}$ and is time-homogeneous. Denote the distribution by $P\left(\theta_{t} \mid \theta_{t-1}, e_{t-1}\right)$. The distribution of $\theta_{0}$ is given by $P_{0}(\cdot)$. Given $\theta_{t}$, the principal gets the outcome $y_{t}=y\left(\theta_{t}\right)$ as a deterministic function of the productivity. A performance outcome is $\phi_{t}=\left(\theta_{t}, y_{t}, \theta_{t+1}\right)$. Note that the outcome need not be deterministic. I assume it to be deterministic to simplify the analysis, but the same argument works if it is stochastic and the expected outcome is a function of the state.

The timing of the model is the following. At the beginning of period $t$, the principal 
offers a contract to the agent, and the agent decides whether to accept it. The outcome is realized as a function of the productivity, which is known from previous period. The agent decides how much effort to exert, and the productivity for the next period is realized. The principal and the agent make the payments.

We have the following versions of Proposition 1-3. The proofs are in the appendix.

Proposition 6. Suppose there exists a relational contract with expected joint surplus $s>\bar{s}$. Any expected payoff pair $(u, \pi)$ with $u \geq \bar{u}, \pi \geq \bar{\pi}, u+\pi=s$ can be implemented with $a$ relational contract.

The proof of Proposition 6 is the same as the proof of Proposition 1 verbatim. The agent accepts the contract as long as the expected payoff is greater than his outside option, and the principal can always redistribute the surplus by the fixed wage.

Proposition 7. The maximum joint surplus can be attained with a stationary contract. Furthermore, it is optimal to provide the same expected payoff to the agent in every state.

The key to the proof of Proposition 7 is that $\theta^{\prime}$ is a sufficient static about the outcome and states from the next period. Since the principal and the agent are risk-neutral and the productivity is observed before they make the payments, the principal can provide all incentives by the present compensation and provide a constant expected payoff to the agent in every state. Under an optimal contract, the expected joint surplus for given state $\theta$ is constant, and the principal can choose the bonus payments to maximize the expected joint surplus.

Proposition 8. An effort schedule $e(\theta)$ with expected joint surplus $s(\theta)$ can be implemented with a stationary contract, with a constant expected payoff to the agent, if and only if there exists a payment schedule $W: \Phi \rightarrow \mathbb{R}$ such that for all $\theta \in \Theta$,

$$
\begin{aligned}
& (I C) \quad e(\theta) \in \arg \max _{e} \mathbb{E}_{y, \theta^{\prime}}[W(\phi) \mid e, \theta]-c(e, \theta) \\
& (D E) \quad \frac{\delta}{1-\delta}\left(s\left(\theta^{\prime}\right)-\bar{s}\right) \geq \sup _{\theta, y} W\left(\theta, y, \theta^{\prime}\right)-\inf _{\theta, y, \theta^{\prime}} W\left(\theta, y, \theta^{\prime}\right) .
\end{aligned}
$$

In Proposition 8, the bonus cap now depends on the realization of the productivity for the next period. This is because the bonus payment is contingent on the productivity for the next period, which is the sufficient static for the expected joint surplus. The rest of the argument is the same as in the proof of Proposition 3.

Remark 1. When the states are observable to both the principal and the agent, even if the states are endogenous, the optimal relational contracts are stationary. There is no information asymmetry about the distirbution of future states, and together with risk-neutrality, we 
obtain the stationarity theorem and the necessary and sufficient condition to implement an effort schedule.

Remark 2. The difference between the endogenous states and the exogenous states is that instead of having a uniform bonus cap for the given state with exogenous states, the bonus cap now depends on the realization of the productivity for the next period when they are endogenous.

Remark 3. With exogenous states, the optimal relational contract either implements the first best or is a step function. This no longer holds for endogenous states.

\section{Joint Surplus in the Second Best}

I consider the joint surplus in the second best for two types of persistence in this section. The states are exogenous. The first case is in which the joint surplus in the first best increases with the state. When the cost function is separable and strictly decreases with the state, incentive provision is identical in each state, and in particular, given a bonus cap, the principal can implement the same level of effort in every state. The second type of persistence I consider is when the incentive provision becomes easier in a higher state. The joint surplus in the first best is identical in all states. In both cases, the difference in joint surplus between the first best and the second best decreases with the state. The principal prefers relational contracts only if the initial state is sufficiently high.

\subsection{Joint Surplus Varies with the State}

In this section, I consider the case in which the joint surplus varies with the state and the incentive provision is constant across the states. Specifically, I assume the following.

Assumption 4. The cost of effort is separable and strictly decreases with the state: there exist $c_{1}: \mathcal{E} \rightarrow \mathbb{R}, c_{2}: \Theta \rightarrow \mathbb{R}$ such that

$$
c(e, \theta)=c_{1}(e)+c_{2}(\theta), \forall e \in \mathcal{E}, \theta \in \Theta
$$

and $c_{2}^{\prime}<0$ for all $\theta \in \Theta$.

Assumption 5. $F(\cdot \mid e, \theta)$ is independent of $\theta$.

Assumption 6. $\theta_{t}>\theta_{t}^{\prime}$ implies $P\left(\cdot \mid \theta_{t}\right)$ FOSD $P\left(\cdot \mid \theta_{t}^{\prime}\right)$. 
I also define $\Delta W(\theta)$ as the minimum bonus cap necessary to be able to induce the first best level of effort in state $\theta$. Given a state $\theta, e^{F B}(\theta)$ can be a solution to

$$
\begin{aligned}
& e(\theta) \in \arg \max _{e} \mathbb{E}_{y}[W(\phi) \mid e]-c(e, \theta), \\
& \Delta W \geq \sup _{y} W(\theta, y)-\inf _{y} W(\theta, y)
\end{aligned}
$$

if and only if $\Delta W \geq \Delta W(\theta)$.

As a benchmark, I first show the implications of Assumption 4 in the first best and in the case the principle has a within-period commitment power.

Proposition 9. Suppose Assumption 4, 5 and 6 hold. The expected joint surplus in the first best strictly increases with the state, both in per period and in the future discounted joint surplus. The first best level of effort is constant across all states $\theta \in \Theta$. The minimum bonus cap to implement the first best level of effort, $\Delta W(\theta)$, is also constant across the state. If the principal can credibly promise $W(\phi)$, the principal implements one level of effort, $e^{*}=e^{F B}$ in all states.

Proof. The expected joint surplus in state $\theta$ is given by

$$
\mathbb{E}_{y}[y \mid e]-c(e, \theta)=\mathbb{E}_{y}[y \mid e]-c_{1}(e)-c_{2}(\theta)
$$

and the first best level of effort is the maximand of

$$
\int_{y} y f(y \mid e) d y-c_{1}(e)-c_{2}(\theta)
$$

Since the cost of effort is separable, the maximization problems for any two states are constant transformations of each other, and the first best level of effort is constant across the states. The cost strictly decreases with the state, and the expected per period joint surplus in the first best in state $\theta$ strictly increases with the state. By the persistence of states, the future discounted joint surplus also increases with the state. Since the maximization problems are a constant transformation of each other, $\Delta W(\theta)$ is constant across the states.

If the principal can commit to bonus payments, the only constraint is the agent's IC constraint. By the efficiency assumption, it is efficient to induce the first best level of effort than to take the outside option in all states $\theta$, and the principal induces the first best level of effort in all $\theta$.

Now consider relational contracts under Assumption 4. Define $s^{F B}(\theta)$ as the discounted future joint surplus when the previous state is $\theta$. We know from Proposition 9 that $\Delta W(\theta)$ 
is constant over $\theta$. Denote $\Delta W(\theta)=\Delta W^{*}$. If $s^{F B}(\underline{\theta}) \geq \Delta W^{*}$, the principal can implement the first best level of effort in all states with relational contracts, and the problem becomes trivial. I will make the following assumption:

Assumption 7. The principal cannot induce the first best level of effort in the lowest state:

$$
s^{F B}(\underline{\theta})<\Delta W^{*}
$$

Define $e(\theta \mid \Delta W)$ to be the solution to the optimization problem

$$
\begin{array}{r}
\max _{e} \mathbb{E}_{y}[y-c \mid e, \theta] \quad \text { s.t. } e(\theta) \in \arg \max _{e} \mathbb{E}_{y}[W(\phi) \mid e]-c(e, \theta), \\
\Delta W \geq \sup _{y} W(\theta, y)-\inf _{y} W(\theta, y) .
\end{array}
$$

$e(\theta \mid \Delta W)$ is the level of effort that maximizes the per period joint surplus in state $\theta$ when the bonus cap is $\Delta W$. If $\Delta W \leq \Delta W(\theta)$, the principal cannot implement the first best level of effort, and $e(\theta \mid \Delta W)<e^{F B}(\theta)$. Since the principal can always mimic the payments with $\Delta W^{\prime}$ if $\Delta W \geq \Delta W^{\prime}$, the implemetable level of effort weakly increases with the bonus cap, and we have $e(\theta \mid \Delta W) \geq e\left(\theta \mid \Delta W^{\prime}\right), \forall \theta$.

Proposition 10. The implementable level of effort $e(\theta \mid \Delta W)$ weakly increases with $\Delta W$ for all $\theta$.

Proof. The proof follows from the fact that the principal can always mimic the compensation scheme with $\Delta W^{\prime}$ if $\Delta W \geq \Delta W^{\prime}$.

Under relational contracts, the expected joint surplus from the following period limits the principal's ability to induce effort, and Assumption 4 states that the joint surplus in the first best strictly increases with the state. The implementable level of effort is lower in a worse state, and the difference in the expected joint surplus is reinforced by the implementable effort. Under Assumption 4, the joint surplus under relational contracts increases with the state, and the difference in the joint surplus between the first best and the second best decreases with the state.

Proposition 11. Suppose Assumption 4, 5, 6 and 7 hold. Let $s^{S B}(\theta)$ be the expected joint surplus under an optimal relational contract. $s^{S B}(\theta)$ strictly increases with $\theta$, and $\frac{\partial s^{S B}}{\partial \theta} \geq$ $\frac{\partial s^{F B}}{\partial \theta}>0$. The difference in the joint surplus between the first best and the second best, $s^{F B}(\theta)-s^{S B}(\theta)$, weakly decreases with the state. The difference is strictly positive at $\underline{\theta}$, and it is weakly bigger than zero at all $\theta$. 
Proof. We know from Proposition 10 that the implementable level of effort, $e(\theta \mid \Delta W)$, weakly increases with $\Delta W$. From Assumption 4, the expected joint surplus in the first best increases with the state, and Assumption 7 says that the expected joint surplus in the state $\underline{\theta}$ is less than the minimum bonus cap to induce the first best level of effort. Since the distribution of the states increases with the state in the sense of first-order stochastic dominance, the implementable level of effort under an optimal relational contract increases with the state, and the expected joint surplus in the second best also increases with the state.

Consider the difference in per period joint surplus between the first best and the second best.

$$
\begin{aligned}
& S\left(e^{F B}, \theta\right)-S(e(\theta \mid \Delta W), \theta) \\
= & \left(\mathbb{E}\left[y \mid e^{F B}\right]-c\left(e^{F B}, \theta\right)\right)-(\mathbb{E}[y \mid e(\theta \mid \Delta W)]-c(e(\theta \mid \Delta W), \theta)) \\
= & \left(\mathbb{E}\left[y \mid e^{F B}\right]-c_{1}\left(e^{F B}\right)\right)-\left(\mathbb{E}[y \mid e(\theta \mid \Delta W)]-c_{1}(e(\theta \mid \Delta W))\right) .
\end{aligned}
$$

Given $\Delta W, e(\theta \mid \Delta W)$ is constant across the states, and we also know that

$$
\mathbb{E}[y \mid e(\theta \mid \Delta W)]-c_{1}(e(\theta \mid \Delta W))
$$

increases with $\Delta W$. Therefore, the difference in the per period joint surplus,

$$
S\left(e^{F B}, \theta\right)-S(e(\theta \mid \Delta W), \theta)
$$

decreases with the state, and by the persistence of the states, the difference in the expected joint surplus also decreases with the state. From Assumption 7, the difference is strictly positive at $\underline{\theta}$.

When the per period joint surplus in the first best increases with the state, the persistence of the states enter the optimization problem through the bonus cap, and the expected joint surplus under an optimal relational contract also increases with the state. The dynamic enforcement constraint magnifies the impact of persistent states, and the expected joint surplus varies more in the second best than in the first best.

\subsection{Incentive Provision Varies with the State}

This section considers the alternative case in which the joint surplus in the first best is constant across the state but the incentive provision varies with the state.

I assume that the first best level of effort is constant across the states. This is without

loss of generality for any interior solution $e^{F B}$. I also assume that for given bonus cap, the 
maximum per period joint surplus strictly increases with the state, and the principal cannot implement the first best level of effort in the worst state, even with the expected joint surplus in the first best.

Assumption 8. The first best level of effort is constant in all states. The per period joint surplus in the first best is constant across the states: $S\left(e^{F B}, \theta\right)=S^{*}$ for all $\theta$.

Assumption 9. For given bonus cap $\Delta W$, if the principal cannot induce the first best level of effort, the maximum per period joint surplus strictly increases with the state. i.e., $S(e(\theta \mid \Delta W), \theta)$ strictly increases with $\theta$ for all $e(\theta \mid \Delta W)<e^{F B}$.

Assumption 10. The principal cannot implement the first best level of effort in the lowest state, and $e\left(\underline{\theta} \mid s^{F B}\right)<e^{F B}$.

Under the second set of assumptions, the expected joint surplus in the second best strictly increases with the state, and the difference in the expected joint surplus between the first best and the second best decreases with the state. We have the following proposition which is an analogue of Proposition 11.

Proposition 12. Suppose Assumption 6, 8, 9 and 10 hold. There exists $\theta^{*} \in \Theta$ such that $s^{S B}(\theta)$ strictly increases with $\theta$ for $\theta<\theta^{*}$, and $s^{S B}(\theta)=s^{F B}$ for $\theta \geq \theta^{*}$. The difference in the joint surplus between the first best and the second best, $s^{F B}-s^{S B}(\theta)$, decreases with the state. The difference is strictly positive at $\underline{\theta}$, and it is weakly bigger than zero at all $\theta$.

Proof. By Assumptions 9, 10 and the persistence of the states, the per period joint surplus in the second best weakly increases with $\theta$, and it increases strictly for all $\theta$ such that $e\left(\theta \mid s^{S B}(\theta)\right)<e^{F B}$. Therefore, the expected joint surplus in the second best also increases with the state. Since the first best joint surplus is constant across the states, the difference between the first best and the second best decreases with the state.

I have considered two types of persistent states. In both environments, the difference in the expected joint surplus between the first best and the second best decreases with the state. If the two factors, the level of joint surplus in the first best and the difficulty of incentive provision, move in the same direction, the effect will be magnified. If they move in the opposite directions, the difference in the joint surplus will be determined by which effect dominates.

\subsection{Benefits from Relational Contracts}

Suppose there exists a positive benefit from relational contracts. I define full-commitment contracts as contracts under which the principal specifies the compensation scheme as functions of history and commit to both the fixed wage and the bonus payments. In my model, 
the only constraint under full-commitment contracts is the agent's IC constraints, and the principal can implement the first best under full-commitment contracts.

There could be gains from relational contracts as it is often impractical to write complete contracts. Performance measures can be hard to describe, and often, the best performance measure is a subjective measurement. When there is positive benefit $x>0$ from relational contracts, the principal prefers the relational contracts over full-commitment contracts if and only if the benefit is bigger than the difference in the expected joint surplus.

Proposition 13. Suppose Assumptions 4 to 7 hold. Let $x>0$ be the benefit from relational contracts. The principal prefers relational contracts if and only if the prior on the states is sufficiently high:

$$
\int_{\theta_{0}} s^{S B}\left(\theta_{0}\right) d P_{0}\left(\theta_{0}\right)+x \geq \int_{\theta_{0}} s^{F B}\left(\theta_{0}\right) d P_{0}\left(\theta_{0}\right) .
$$

Proof. The principal can implement the first best with full-commitment contracts. Given prior $P_{0}$ on the state, the difference in the expected joint surplus between the full-commitment contract and the optimal relational contract is given by

$$
\int_{\theta_{0}}\left(s^{F B}\left(\theta_{0}\right)-s^{S B}\left(\theta_{0}\right)\right) d P_{0}\left(\theta_{0}\right)-x .
$$

Proposition 14. Suppose Assumption 6, 8, 9 and 10 hold. Let $x>0$ be the benefit from relational contracts. The principal prefers relational contracts if and only if the prior on the states is sufficiently high:

$$
\int_{\theta_{0}} s^{S B}\left(\theta_{0}\right) d P_{0}\left(\theta_{0}\right)+x \geq s^{F B} .
$$

Proof. The principal can implement the first best with full-commitment contracts, and the joint surplus in the first best is constant.

\section{Market for Matching}

This section considers a market for matching when there is a continuum of principal-agent pairs. In any given period, the principal and the agent have an option to exit the current relationship. If they exit, they will be randomly, anonymously and costlessly rematched with new partners. The main result of this section is that the nature of the underlying state leads to different implications for the market. If the state is agent-specific, the principal-agent pairs remain in the current relationships regardless of the realization of the state or the past history, and there will be no market for matching. If the state is relationship-specific, there 
will be a market, and the pair leaves the relationship if and only if the expected joint surplus falls below some threshold. If the state is a macro shock, common to all principal-agent pairs, then cooperation is impossible, and the principal cannot induce the agent to put in any effort. Cooperation is also impossible if the states are i.i.d..

The literature on relational contracts take the outside options as exogenous. The goal of this section is to consider the market and to endogenize the outside options. If a continuum of principal-agent pairs in the same contractual environment have options to be matched with new partners, the market forms endogenous outside options for the principal-agent pairs. The implications highlight the difference between the i.i.d. states and persistent states, and also the difference among the types of persistent states.

The timing of the game is the following. In each period, the principal offers a compensation scheme, and the agent decides whether or not ot accept it. After the agent decides, the state is realized and becomes observable to both the principal and the agent. If the agent accepted, he decides how much effort to put in, and the outcome is realized. The principal and the agent make the contingent bonus payment and decide whether or not to stay in the relationship. If they both decide to stay, they move on to the next period. If one of them exists, both the principal and the agent will be matched with new partners and start in the next period. If the agent rejected the offer, both receive their exogenous outside options and decide whether to stay or exit.

With a market for matching, the outside options for the principal and the agent are endogenously determined in an equilibrium. However, given a continuum of principal-agent pairs, each pair takes the outside options as given, and we can apply the analysis from Section 3. I allow for exogenous outside options as well, but this doesn't affect the analysis, and we can restrict attention to endogenous outside options if desired. ${ }^{3}$ In this section, $\bar{s}$ refers to the endogenous outside option through matching.

The equilibria of the game depend on the strategies when the principal and the agent are matched with new partners. For most part of this section, I focus on equilibria in which the principal and the agent always maximize the joint surplus, when they are matched with new partners. I will discuss at the end of the section what happens if they don't maximize the joint surplus. Also, the analysis in this section doesn't rely on the stationarity or symmetry of the strategies. The principal-agent pairs are allowed to use non-stationary contracts, and each pair can use different contracts.

\footnotetext{
${ }^{3}$ Without loss of generality, we can assume that if the principal anticipates that the agent will reject the offer in the next period, he chooses to exit the relationship.
} 


\subsection{When the States are i.i.d.}

This section considers the i.i.d. states as a benchmark. Cooperation is impossible if there is frictionless market for matching and if the principal-agent pairs maximize the joint surplus in a new relationship.

Proposition 15. Suppose the states are i.i.d., and the principal and the agent can be randomly, anonymousy, and costlessly matched with new partners. If the principal-agent pairs maximize the joint surplus in a new relationship, the principal cannot induce any level of effort from the agent.

Proof. After the outcome is realized, the principal makes the bonus payment if and only if

$$
\frac{\delta}{1-\delta}(\pi-\bar{\pi}) \geq \sup _{y} b(\theta, y), \forall \theta
$$

and the agent makes the bonus payment if and only if

$$
\frac{\delta}{1-\delta}(u-\bar{u}) \geq-\inf _{y} b(\theta, y), \forall \theta
$$

Together, we have

$$
\frac{\delta}{1-\delta}(s-\bar{s}) \geq \sup _{y} b(\theta, y)-\inf _{y} b(\theta, y)
$$

However, if they maximize the joint surplus when matched with new partners and the states are i.i.d., $s=\bar{s}$, and the bonus payment has to be the same for all outcomes. The agent has no incentive to put in any effort.

Note that I don't require the strategies to be stationary or symmetric. The only requirement is that the princpial and the agent maximize the joint surplus when they are matched with new partners, but when they do, they can't have any level of cooperation. In order to have any cooperation, they cannot maximize the joint surplus when they are matched with new partners; this case is considered in Section 6.5. Also note that, in order to have cooperation, they have to supress the joint surplus. Delaying the payment doesn't help.

\subsection{Relationship-Specific State}

Suppose that the states are persistent and the state is specific to the pair of principal and agent. If they exit the current relationship, the initial state in a new relationship is drawn from a known distribution $G$ and is i.i.d. across the new pairs of principals and agents. Then there is endogenous threshold for the joint surplus such that the principal and the agent exit the relationship if and only if the expected joint surplus falls below the threshold. 
Proposition 16. Suppose the initial state is i.i.d. across the new pairs of principals and agents and is drawn from a known distribution $G$. The principal and the agent exit the current relationship if and only if the expected joint surplus falls below some threshold. When the state is such that they will exit, the agent doesn't put in any effort.

Proof. From Section 3, the principal and the agent stay in the relationship if and only if $s(\theta) \geq \bar{s}$, where $\bar{s}$ is the expected joint surplus from being matched with a new partner. If $s(\theta)<\bar{s}$, the bonus payment is the same for all outcomes, and the agent doesn't put in any effort.

When the state is specific to the principal-agent pair, they remain in the relationship if and only if the expected joint surplus is above the threshold. Since the states are observable and the principal and the agent maximize the joint surplus, the state in this period completely summarizes the expected joint surplus from the next period and on, and the exit behavior is determined by the realization of the state.

Contrary to the i.i.d. case, there is some degree of cooperation in any equilibrium, except for the degenerate case in which the expected joint surplus from the new distribution $G$ dominates the expected joint surplus after any state. Even if the principal and the agent maximize the joint surplus in every relationship, the principal can induce the agent to exert effort in a good enough state.

\subsection{Agent-Specific State}

Next, consider the case in which the state is the type of the agent. It can be interpreted as the productivity of the agent. When the agent is matched with a new principal, the distribution of the state is determined by his type in the last period, which is the last realizaiton of the state in the agent's previous relationship. In this case, I show the market for matching turns into the market for lemons; there cannot be a market for matching, and all principal-agent pairs stay in their relationship forever.

Proposition 17. Suppose when a principal and an agent is matched, the initial state is drawn from the distribution $P(\cdot \mid \theta)$ where $\theta$ is the last realization of the state of the agent. The principal and the agent never exit the current relationship, and there is no market for rematching.

Proof. From Section 3, we can focus on the joint surplus from the relationship, and the principal and the agent remain in the current relationship if and only if $s(\theta) \geq \bar{s}$. Let $\hat{\Theta}=\{\theta \mid s(\theta)<\bar{s}\} \subset \Theta$ be the set of states after which the principal and the agent exit the 
relationship. Let $F$ be the distribution of the states in the given period. When the principal and the agent decide whether to stay in the relationship, the outside option must satisfy

$$
\bar{s}=\int_{s \in \hat{\Theta}} s(\theta) d F
$$

which is a contradiction to the definition of $\hat{\Theta}$. Therefore, $\hat{\Theta}$ is degenerate and can only be $\emptyset$.

If the principal and the agent maximize the joint surplus when they are matched with new partners, the lowest type is indifferent between staying in and exiting the relationship. When the realized state is such, the parties cannot make any bonus payment, and the agent puts in no effort. If they don't maximize the joint surplus, even the lowest type prefers to stay in the current relationship. The principal and the agent never exit the relationship, and there is no market for rematching.

Proposition 17 shows that if the underlying state is the type of the agent, the market for matching turns into a market for lemons, and there will not be a market. Only the lowest type can exist in the market, and all principal-agent pairs stay in the current relationship.

Note that the result doesn't depend on the strategies of the principal-agent pairs when matched with new partners. Proposition 17 holds even if the principal and the agent don't maximize the joint surplus in new relationships.

\subsection{Macro Shock}

This section considers a macro shock. The state is common to all principal-agent pairs. In this case, the principal cannot induce the agent to put in any effort, and cooperation is impossible.

Proposition 18. Suppose the state is common to all principal-agent pairs. If the principal and the agent maximize the joint surplus in every relationship, the principal cannot induce the agent to put in any effort.

Proof. The proof is the same as in the i.i.d. case. If the state is common to all principalagent pairs, $s=\bar{s}$ in the dynamic enforcement constraint, and the principal pays the same bonus for all payments. The agent has no incentive to put in any effort.

If the state is common to all principal-agent pairs, the expected joint surplus from the next period and on is the same whether they remain in the current relationship or are matched with new partners. Then, the principal and the agent have no incentive to pay the bonus payment, and without the bonus payments, cooperation is impossible. 


\subsection{Not Maximizing the Joint Surplus}

This section discusses what happens when the principal and the agent don't maximize the joint surplus when they are matched with new partners. The degree of cooperation depends on the endogenous outside option determined in a market, and the maximum cooperation the principal and the agent can have weakly decreases with the outside option. The maximum cooperation is possible if they revert to the static equilibrium when matched with new partners. However, any equilibrium in which the pairs don't maximize the joint surplus is not renegotiation proof.

Proposition 19. The maximum joint surplus weakly decreases with the outside option $\bar{s}$ determined in an equilibrium. The maximum joint surplus is the largest if the principal and the agent revert to the static equilibrium when matched with new partners. Ex ante maximum joint surplus also weakly decreases with the outside option.

Proof. We know from Section 3 that without a market, the joint surplus decreases with the outside option $\bar{s}$. When there is a market, if $s(\theta)<\bar{s}$, the principal and the agent cannot make any bonus payment in that period, the agent puts in no effort, and the parties exit the relationship at the end of the period. When $\bar{s}$ increases, the set of states after which the relationship ends increases. Increase in $\bar{s}$ also means that the bonus cap in a given state is lower, and the per period joint surplus the principal can induce is weakly lower. Together, the maximum joint surplus in every state weakly decreases with $\bar{s}$. Since the endogenous outside option is the minimum when the parties revert to the static equilibrium, the parties can attain the maximum joint surplus if they revert to the static equilibirum in new relationships. When the maximum joint surplus in each state weakly decreases with the outside option, ex ante maximum joint surplus also weakly decreases.

We know from Proposition 1 that the distribution of joint surplus doesn't affect efficient contracting. If the parties are not maximizing the joint surplus, they can always renegotiate and redistribute the surplus. The only contracts that are renegotiation-proof are the ones that maximize the joint surplus in every relationship, and for such contracts, I have shown the following.

Remark 4. When there is a market for matching, the persistence of states leads to very different outcomes from the i.i.d. states. If the principal and the agent always maximize the joint surplus, and if there is a frictionless market for matching, cooperation is impossible with i.i.d. states or macro shocks. On the contrary, there is always some degree of cooperation with relationship-specific states, and there is no market if the states are specific to the agent. 
Remark 5. Ex ante joint surplus is strictly lower with the market, if the states are i.i.d. or common to all principal-agent pairs and if the principal and the agent always maximize the joint surplus. The market doesn't affect the ex ante joint surplus with agent-specific states. The effect of market on ex ante joint surplus is ambiguous for relationship-specific states.

When the states are specific to the relationship, there are two effects of a market on ex ante joint surplus. There are some states in which the agent puts in no effort because the principal and the agent will exit the relationship, but they can also have a new draw instead of staying in the low states. The overall effect depends on which effect dominates.

\section{Conclusion}

I study relational contracts in a persistent environment in this paper. I find that many of the general properties of the optimal relational contracts in i.i.d. states carry over to persistent states, if there is no asymmetric information about the state. The benchmark is when the states are observable and exogenously given. When the states follow a first-order Markov chain, the state in any given period is a sufficient static for the distribution of future states. In particular, the outcome doesn't have any information about the distribution of future states, and the principal can provide the incentives by the bonus payments in the given period. It is optimal to provide the same expected per period payoff in every state.

If the continuation contract for a given state in some period provides the maximum joint surplus for the given state, the principal can provide the same continuation contract in every period for the given state. Since the agent gets the same expected payoff in all states, the agent's IC constraints are still satisfied when the principal replaces the continuation contract, and the optimal contract can be stationary. The principal can also redistribute the surplus through the fixed wage, and we get the dynamic enforcement constraint as with i.i.d. states. An effort schedule can be implemented with stationary contracts if and only if it satisfies the

IC constraint and the dynamic enforcement constaint. As was the case with i.i.d. states, the principal can either implement the first best effort, or the optimal contract takes the form of a step function.

The properties of the optimal contracts hold for endogenous states if the states are observable. The maximum joint surplus can be attained with a stationary contract when the productivity is the state variable. When the productivity is observed before the principal makes the payment, there is no information asymmetry about the state. The agent's effort affects the distribution of future states, but given the productivity for the next period, the principal and the agent have symmetric information about the distribution of future states. The principal can adjust the present compensation and provide the incentives by bonus 
payments, while keeping the expected payoff constant. Then, the incentive provision in each state becomes myopic, and the principal can offer a stationary contract and maximize the joint surplus. A version of dynamic enforcement constraint, together with the IC constraint, is the necessary and sufficient condition to implement an effort schedule with such stationary contracts.

Persistent states can affect the relational contracts through two mechanisms. The persistence of the states implies that if the joint surplus depends on the state, the bonus cap also varies with the state, and the implementable level of effort depends on the state, even if the incentive provision for the given bonus cap is identical in each state. On the other hand, the incentive provision for the given bonus cap can also change with the state. If the joint surplus in the first best increases with the state, or if the implementable level of effort for given bonus cap increases with the state, the difference in the joint surplus between the first best and the second best decreases with the state. The principal prefers the relational contracts to full-commitment contracts only if the initial state is sufficiently high.

I show that the nature of the state has starkly different implications for the market when the principal and the agent can be randomly, anonymously, and costlessly matched with new partners. Cooperation is impossible if the states are i.i.d. and the parties maximize the joint surplus in every relationship. If the states are persistent, we get varying degree of cooperation depending on the type of the state. If it's agent-specific, the principal and the agent stay in the relationship forever, and there is no market. If it's relationship-specific, they exit the current relationship if and only if the expected joint surplus falls below some threshold. With macro shocks, cooperation is impossible, and the principal cannot induce any level of effort.

I have considered partially persistent environments where the states are observable and the persistence is of first-order. If the states are observable, both with exogenous and endogenous states, the optimal contract can be stationary. However, if the states are unobservable, there can be information asymmetry between the principal and the agent about the future states. The belief about the agent's effort matters for the future, and the relational contract will likely have to take into account the private information. It will be interesting to study relational contracts and their implications for the market when the information about the future states is no longer symmetric.

\section{A Proofs}

Proof of Proposition 6. Consider the relational contract that provides $s$. The principal offers in the initial period $w\left(\theta_{0}\right), b\left(\phi_{0}\right)$, and if the agent accepts, he exerts effort $e\left(\theta_{0}\right)$. The 
continuation payoffs under the contract are denoted by $u\left(\phi_{0}\right)$ and $\pi\left(\phi_{0}\right)$, and the expected payoffs from the contract are $u_{0}$ and $\pi_{0}$. Without loss of generality, we can assume that off the equilibrium path, the parties revert to the static equilibrium of $(\bar{u}, \bar{\pi})$. The first period payment $W$ is a function of $\phi_{0}$.

The contract is self-enforcing if and only if the following conditions hold:

$$
\begin{aligned}
& \text { (i) } u_{0} \geq \bar{u}, \pi_{0} \geq \bar{\pi} \text {, } \\
& \text { (ii) } e\left(\theta_{0}\right) \in \arg \max _{e} \mathbb{E}_{\theta_{1}}\left[(1-\delta) W\left(\phi_{0}\right)+\delta u\left(\phi_{0}\right) \mid e, \theta_{0}\right]-c\left(e, \theta_{0}\right) \text {, } \\
& \text { (iii) } b\left(\phi_{0}\right)+\frac{\delta}{1-\delta} u\left(\phi_{0}\right) \geq \frac{\delta}{1-\delta} \bar{u} \\
& -b\left(\phi_{0}\right)+\frac{\delta}{1-\delta} \pi\left(\phi_{0}\right) \geq \frac{\delta}{1-\delta} \bar{\pi},
\end{aligned}
$$

and (iv) each continuation contract is self-enforcing.

Given any $(u, \pi)$ such that $u \geq \bar{u}, \pi \geq \bar{\pi}, u+\pi=s$, the principal can offer the same $b\left(\phi_{0}\right)$ and continuation contracts and adjust $w\left(\theta_{0}\right)$ to

$$
\hat{w}\left(\theta_{0}\right) \equiv w\left(\theta_{0}\right)+\frac{\pi-\pi_{0}}{1-\delta}
$$

The conditions are satisfied with the new contract, and it provides $(u, \pi)$ as the expected payoffs.

Proof of Proposition 7. Suppose a contract that maximizes the joint surplus provides $w_{t}, b_{t}$ and the agent chooses $e_{t}$. The first step is to construct an alternative contract $\hat{w}_{t}, \hat{b}_{t}$ under which the agent chooses the same level of effort $e_{t}$ and his expected payoff is constant in every state.

When the states are observable, the distribution of the states from period $t+1$ only depends on $\theta_{t+1}$, which is observed before the principal makes payments in period $t$. The principal can adjust the contingent payment $b_{t}$ and keep the expected payoff in each state constant. Specifically, consider the following contract. Let $u_{t}\left(h^{t}, \phi_{t}\right)$ be the continuation value of the agent under the given contract, and define $\hat{w}_{t}, \hat{b}_{t}$ as the following:

$$
\begin{aligned}
& \hat{b}_{t}\left(h^{t}, \phi_{t}\right) \equiv b_{t}\left(h^{t}, \phi_{t}\right)+\frac{\delta}{1-\delta}\left(u_{t}\left(h^{t}, \phi_{t}\right)-\bar{u}\right), \\
& \hat{w}_{t}\left(h^{t}, \theta_{t}\right) \equiv \bar{u}-\mathbb{E}_{\theta_{t+1}}\left[\hat{b}_{t}\left(h^{t}, \phi_{t}\right) \mid e_{t}\left(h^{t}, \theta_{t}\right)\right] .
\end{aligned}
$$

From

$$
\hat{b}_{t}\left(h^{t}, \phi_{t}\right)+\frac{\delta}{1-\delta} \bar{u}=b_{t}\left(h^{t}, \phi_{t}\right)+\frac{\delta}{1-\delta} u_{t}\left(h^{t}, \phi_{t}\right),
$$


the agent chooses the same level of effort $e_{t}$ under the new contract. The agent's expected payoff is $\bar{u}$ for all $t, h^{t}, \theta_{t}$.

The next step is to show that we can choose $\tilde{w}: \Theta \rightarrow \mathbb{R}, \tilde{b}: \Phi \rightarrow \mathbb{R}$ such that the principal offers $\tilde{w}, \tilde{b}$ in every period. Consider $\hat{w}_{t}$ and $\hat{b}_{t}$. The agent's expected payoff is constant over all $t, h^{t}$, and $\theta_{t}$, which implies that the agent's IC constraint is determined by the within period compensation scheme. Specifically, the agent chooses $e$ such that

$$
e_{t}\left(h^{t}, \theta_{t}\right) \in \arg \max _{e} \mathbb{E}_{\theta_{t+1}}\left[\hat{b}_{t}\left(h^{t}, \phi_{t}\right) \mid e, \theta_{t}\right]-c\left(e, \theta_{t}\right)
$$

When the agent's IC constraints are myopic, the principal can replace a compensation scheme for any given period with another compensation scheme without affecting the incentives. Under an optimal contract, $s_{t}\left(\theta_{t}\right)$ is constant for given state $\theta_{t}$. If there's multiplicity of the compensation schemes, we can pick one without loss of generality.

Given $\tilde{b}: \Phi \rightarrow \mathbb{R}$, the agent chooses $e: \Theta \rightarrow \mathcal{E}$ such that

$$
e\left(\theta_{t}\right) \in \arg \max _{e} \mathbb{E}_{\theta_{t+1}}\left[\tilde{b}(\phi) \mid e, \theta_{t}\right]-c\left(e, \theta_{t}\right)
$$

Define $\tilde{w}$ as

$$
\tilde{w}\left(\theta_{t}\right) \equiv \bar{u}-\mathbb{E}_{\theta_{t+1}}\left[\tilde{b}(\phi) \mid e\left(\theta_{t}\right), \theta_{t}\right]
$$

and we have a stationary contract that maximizes the expected joint surplus. By construction, it is self-enforcing, and it provides the same expected payoff to the agent in all $t, h^{t}, \theta_{t}$.

Proof of Proposition 8. $(\Rightarrow)$ Suppose $e(\theta)$ is implementable with a stationary contract that provides $\hat{u} \geq \bar{u}$ to the agent in every state. Let $\pi\left(\theta^{\prime}\right)$ be the continuation value for the principal when the realized productivity is $\theta^{\prime}$. The IC constraint has to be satisfied, and we know that

$$
\begin{aligned}
\frac{\delta}{1-\delta}\left(\pi\left(\theta^{\prime}\right)-\bar{\pi}\right) & \geq b\left(\theta, y, \theta^{\prime}\right), \forall \theta, \theta^{\prime}, y \\
\frac{\delta}{1-\delta}(\hat{u}-\bar{u}) & \geq-b\left(\theta, y, \theta^{\prime}\right), \forall \theta, \theta^{\prime}, y
\end{aligned}
$$

have to hold. Adding the two inequalities, we have the dynamic enforcement constraint.

$(\Leftarrow)$ Suppose $W(\phi)$ and $e(\theta)$ satisfy the IC constraint and the dynamic enforcement 
constraint. Define

$$
\begin{aligned}
b(\phi) & =W(\phi)-\inf _{\phi} W(\phi), \\
w(\theta) & =\bar{u}-\mathbb{E}_{y, \theta^{\prime}}[b(\phi) \mid e(\theta), \theta],
\end{aligned}
$$

and consider the stationary contract with $w(\theta), b(\phi)$ and $e(\theta)$. The parties revert to the static equilibrium if a deviation occurs. The agent receives $\bar{u}$ as expected payoff in each state, and the principal receives $\pi(\theta)=s(\theta)-\bar{u}$ if the productivity is $\theta$. By the dynamic enforcement constraint, $s(\theta) \geq \bar{s}$ and $\pi(\theta) \geq \bar{\pi}$ for all $\theta$. From the IC constraint, the agent chooses $e(\theta)$ in each state $\theta$, and it can be verified that Inequality (3) and (4) are satisfied.

\section{References}

[1] Athey, Susan, and Kyle Bagwell. "Collusion with Persistent Cost Shocks." Econometrica 76 (2008): 493-540.

[2] Baker, George, Robert Gibbons, and Kevin J. Murphy. "Relational Contracts and the Theory of the Firm." Quarterly Journal of Economics 117 (2002): 39-84.

[3] Battaglini, Marco. "Long-Term Contracting with Markovian Consumers." American Economic Review 95 (2005): 637-58.

[4] Bull, Clive. "The Existence of Self-Enforcing Implicit Contracts." Quarterly Journal of Economics 102 (1987): 147-59.

[5] Eeckhout, Jan. "Minorities and Endogenous Segregation." Review of Economic Studies 73 (2006): 31-53.

[6] Escobar, Juan F., and Juuso Toikka. 2012. "Efficiency in Games with Markovian Private Information." http://economics.mit.edu/faculty/toikka/papers.

[7] Fudenberg, Drew, Bengt Holmstrom, and Paul Milgrom. "Short-Term Contracts and Long-Term Agency Relationships." Journal of Economic Theory 51 (1990): 1-31.

[8] Fujiwara-Greve, Takako, and Masahiro Okuno-Fujiwara. "Voluntarily Separable Repeated Prisoner's Dilemma." Review of Economic Studies 76 (2009): 993-1021.

[9] Garrett, Daniel, and Alessandro Pavan. 2011. "Dynamic Managerial Compensation: On the Optimality of Seniority-based Schemes." http://faculty.wcas.northwestern.edu/ apa522/. 
[10] Garrett, Daniel, and Alessandro Pavan. 2012. "Managerial Turnover in a Changing World." http://faculty.wcas.northwestern.edu/ apa522/.

[11] Ghosh, Parikshit, and Debraj Ray. "Cooperation in Community Interaction Without Information Flows." Review of Economic Studies 63 (1996): 491-519.

[12] Haltiwanger, John, and Joseph E. Harrington, Jr. "The Impact of Cyclical Demand Movements on Collusive Behavior." RAND Journal of Economics 22 (1991): 89-106.

[13] Kranton, Rachel E. "The Formation of Cooperative Relationships." Journal of Law, Economics, and Organization 12 (1996): 214-33.

[14] Kreps, David M. "Corporate Culture and Economic Theory." In Perspectives on Positive Political Economy, edited by James E. Alt and Kenneth A. Shepsle, 90-143. Cambridge: Cambridge University Press, 1990.

[15] Kwon, Suehyun. 2012. "Dynamic Moral Hazard with Persistent States." http://economics.mit.edu/grad/skwon/papers.

[16] Levin, Jonathan. "Relational Incentive Contracts." American Economic Review 93 (2003): 835-57.

[17] MacLeod, W. Bentley, and James M. Malcomson. "Implicit Contracts, Incentive Compatibility, and Involuntary Unemployment." Econometrica 57 (1989): 447-80.

[18] McAdams, David. "Performance and Turnover in a Stochastic Partnership." American Economic Journal: Microeconomics 3 (2011): 107-42.

[19] Rayo, Luis. "Relational Incentives and Moral Hazard in Teams." Review of Economic Studies 74 (2007): 937-63.

[20] Rogerson, William P. "The First-Order Approach to Principal-Agent Problems." Econometrica 53 (1985): 1357-67.

[21] Rotemberg, Julio J., and Garth Saloner. "A Supergame-Theoretic Model of Price Wars during Booms." American Economic Review 76 (1986): 390-407.

[22] Shapiro, Carl, and Joseph E. Stiglitz. "Equilibrium Unemployment as a Worker Discipline Device." American Economic Review 74 (1984): 433-44.

[23] Tchistyi, Alexei. 2006. "Security Design with Correlated Hidden Cash Flows: The Optimality of Performance Pricing." http://faculty.haas.berkeley.edu/Tchistyi/. 
[24] Thomas, Jonathan, and Tim Worrall. "Foreign Direct Investment and the Risk of Expropriation." Review of Economic Studies 61 (1994): 81-108.

[25] Thomas, Jonathan, and Tim Worrall. 2010. "Dynamic Relational Contracts with Credit Constraints." The School of Economics Discussion Paper Series 1009.

[26] Watson, Joel. "Starting Small and Renegotiation." Journal of Economic Theory 85 (1999): 52-90. 